\title{
Spheroidal weathering of columnar-jointed basalt of the Ogura lava in the Takurayama Volcano, western Japan
}

\author{
Yasuto Hirata $^{1, *}$, and Masahiro Chigira ${ }^{2}$ \\ ${ }^{1}$ Central Research Institute of Electric Power Industry, 2701194 Abiko, Chiba, Japan \\ ${ }^{2}$ Disaster Prevention Research Institute, Kyoto University, 6110011 Uji, Kyoto, Japan
}

\begin{abstract}
Spheroidal weathering is an important form of rock weathering and has been attributed to chemical weathering from joint surfaces. However, the effects of the original rock structures on the processes of spheroidal weathering have not been well addressed. A columnar-jointed basalt contains primary structures that resulted from cooling, which exerted strong controls on the development of weathering with hard crusts. The primary structures were small-pore-size layers beneath the surfaces of columnar joints and some cross joints. Weathering of plagioclase was less intense in the small-pore-size layers, resulting in the exfoliation of surface parts of the layers and internal cracks.
\end{abstract}

\section{Introduction}

Spheroidal weathering shows a simple concentric succession of weathering that propagated from surrounding joints into the parent rock, with layers of weathered rock exfoliated from ball-like fresh parts. It has long been recognized as a dominant weathering process in hard rocks, including most igneous rocks [1-3].

Most previous studies of spheroidal weathering have generally supposed the parent rock to be homogeneous [1] and exfoliation of rock to be formed during rock expansion due to chemical weathering $[2,3]$ but some studies have inferred that original structure due to the cooling process also exerts an influence in determining the style of weathering [4]. Columnar joints indicate a rapidly cooled igneous rock, and spheroidal weathering has been recognized with columnar joints in many basaltic lavas [4], as well as in a granite porphyry [3]. In this paper, we elucidate the effects of inhomogeneous rock structures on weathering. We observed joints and weathering features in the field, collected rock samples, and analyzed their pore sizes, porosity, mineralogy, and chemistry.

\section{Geological setting and field observations}

The Takurayama Volcano is one of the Quaternary volcanoes in the San-in region, western Japan $\left(35.33^{\circ} \mathrm{N}, 134.92^{\circ} \mathrm{E}\right)$. This volcano has discharged three basaltic lava layers which

\footnotetext{
*Corresponding author: y-hirata@criepi.denken.or.jp
} 
are known as the Ogura lava, Kinuzuri lava, and Takurayama lava [5]. The Ogura and Kinuzuri lavas were extruded at $0.37 \mathrm{Ma}$, and the Takurayama lava at $0.31 \mathrm{Ma}$, as determined by bulk $\mathrm{K}-\mathrm{Ar}$ dating [6]. The region has $13.7^{\circ} \mathrm{C}$ of mean temperature and $1537.9 \mathrm{~mm}$ of average annual precipitation, as measured by Japan Metrological Agency.

The layer of Ogura basaltic lava (15 m thick) lies between a $3.5 \mathrm{~m}$ thick layer of clinker and scoria that rests directly on the basement rock, and a $1 \mathrm{~m}$ thick layer of clinker that is exposed to the atmosphere at the top of the lava. The lower colonnade of the lava shows well-developed columnar joints and spheroidal corestones (Fig. 1a). The columns were cut into prisms by curved low-angle joints that do not extend into adjoining columns. This type of joint is presumed to be made by thermal stress after columnar jointing and it is called a cross joint [7]. Internal cracks were found at prisms at intersections of columnar joints and cross joints, and they chamfered the edge of prisms. Consequently, this basalt became nearly spheroidal corestones after the exfoliation using cross joints and internal cracks.

The surface parts of prisms surrounded by columnar joints and cross joints revealed color zones and internal cracks. The joint surfaces are yellowish-brown in color or covered with rock varnish, but the band directly under the joint is dark gray, and a few centimeters inside the dark gray band the color becomes a white gray, and finally a light gray in the center of the prism (Fig. 1b and 1c). In this paper, we call these internal rock zones the surface dark layer, the white zone, and the light gray zone.

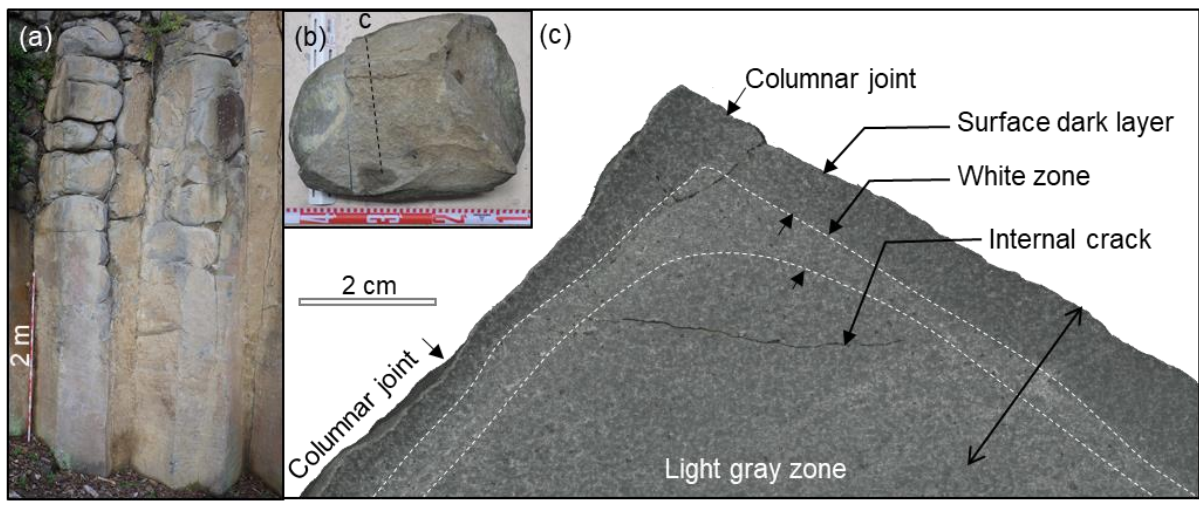

Fig. 1. Sampling of columnar-jointed basalt. (a) Outcrop of the lower colonnade of the Ogura lava. The upper part discloses that curved cross joints separate rock columns vertically. (b) Sample. (c) Cross-section of the sample at its corner, viewed from the columnar axis. Double-headed arrow indicates the transect along which XRD and XRF measurements were made.

\section{Laboratory methods}

Pore-size distributions and porosities were measured using mercury intrusion porosimetry. For each rock zone we made an air-dried specimen of $14 \mathrm{~mm}$ in diameter and $25 \mathrm{~mm}$ long, and set it in a Micrometrics Pore Sizer (model 9320). This instrument records the injection pressure $(p)$ from $3 \mathrm{kPa}$ to $200 \mathrm{MPa}$ together with the amount of mercury injected. According to ASTM D4404-84, we used the contact angle of mercury $(\theta)$ of $140^{\circ}$, the surface tensile stress $(\gamma)$ of $0.480 \mathrm{~N} / \mathrm{m}$, and calculated the pore size $(D)$ with the equation.

$$
D=-4 \gamma \cos \theta / p
$$

The mineralogy of each specimen was analyzed either by thin-section observation or Xray diffraction. Thin sections from the surface parts of samples were cut normal to the columnar joints. The XRD analyses of the air-dried powder samples were performed using a Rigaku MiniFlex600 X-ray diffractometer (X-ray target CuK $\alpha ; 40 \mathrm{kV} ; 10 \mathrm{~mA} ; 0.25$ degrees per second). 
Chemical analyses were conducted to determine $\mathrm{SiO}_{2}, \mathrm{TiO}_{2}, \mathrm{Al}_{2} \mathrm{O}_{3}, \mathrm{Fe}_{2} \mathrm{O}_{3}, \mathrm{MnO}, \mathrm{MgO}$, $\mathrm{CaO}, \mathrm{Na}_{2} \mathrm{O}, \mathrm{K}_{2} \mathrm{O}, \mathrm{P}_{2} \mathrm{O}_{5}$, and $\mathrm{Zr}$ contents. They were measured by X-ray fluorescence (XRF) analysis of glass beads. The glass beads were prepared by mixing a portion of each sample heated to $750^{\circ} \mathrm{C}$ with $\mathrm{Li}_{2} \mathrm{~B}_{4} \mathrm{O}_{7}$ and then fusing the mixture at $1050^{\circ} \mathrm{C}$. The flux ratios were $0.4 \mathrm{~g}$ to $4 \mathrm{~g}$. We used a wavelength-dispersive XRF spectrometer (Shimadzu, XRF-1500) equipped with a $\mathrm{Rh} \mathrm{X}$-ray tube operating at $30 \mathrm{kV}$ and $90 \mathrm{~mA}$.

Elemental transfer coefficients of given element $j\left(\tau_{j}\right)$ expressing chemical depletion or enrichment during weathering is estimated by a mass balance equation using the concentrations of the immobile element such as $\mathrm{Ti}[2,3]$.

$$
\tau_{\mathrm{Ti}, j}=C_{\mathrm{Ti}, \mathrm{p}} C_{j, \mathrm{w}} / C_{\mathrm{Ti}, \mathrm{w}} C_{j, \mathrm{p}}-1
$$

where $C$ is the mass fraction (wt\%), and the subscripts $\mathrm{p}$ and w designate parent rock and weathered rock, respectively.

We measured five specimens of the inner light gray zone from the prism samples and obtained similar Ti concentrations ranging from $1.70 \%$ to $1.73 \%$. Thus, we assume the Ti concentration of the innermost light gray zone to have been distributed homogeneously before weathering, and we then calculated the mass balance in sections across the columnar joints.

\section{Results}

\subsection{Porosity and pore size}

The mercury intrusion tests showed that the porosity is $5.38 \%$ in the light gray zone, $5.39 \%$ in the surface dark layer, and $8.84 \%$ in the white zone. Porosities of the surface dark layers are less than those of the white zones but similar to those of the light gray zones, while the pore sizes in the surface dark layer are much smaller than those in the light gray zone. The median pore-size was $0.159 \mu \mathrm{m}$ in the light gray zone, $0.083 \mu \mathrm{m}$ in the surface dark layer, and $0.267 \mu \mathrm{m}$ in the white band.

\subsection{Mineralogy}

Basalt from the study site contains olivine and plagioclase phenocrysts, and a fine crystalline groundmass of olivine, plagioclase, clinopyroxene, and opaque minerals; ophitic texture was observed. From the white zone to the columnar joints, the amount of olivine that has been transformed to iddingsite increases. Iddingsite, which is a mixture of goethite and smectite, is altered from olivine under watery oxidizing condition [8]. All the olivine phenocrysts have been invaded by iddingsite in the surface of columnar joints.

XRD analysis detected no clay minerals in the light gray zone but $10 \AA$-halloysite in the white zone, and $10 \AA$ and $7 \AA$-halloysite and a small amount of gibbsite on the joint surfaces. Halloysite was not detected in the zone located $0.0-0.5 \mathrm{~cm}$ inside the surface dark layer of Prism, but it was found in the white zone $(1.0-2.5 \mathrm{~cm})$. The diffraction peaks of the other minerals (plagioclase, olivine, and clinopyroxene) decrease significantly on the joint surface.

\subsection{Chemistry}

The element transfer coefficients of all elements ( $\mathrm{Si}, \mathrm{Al}, \mathrm{Fe}, \mathrm{Ca}, \mathrm{Na}, \mathrm{K}, \mathrm{P}, \mathrm{Mn}, \mathrm{Mg}$, and $\mathrm{Zr}$ ) are shown in Fig. 2. Fe, Mn, and $\mathrm{Zr}$ are constant in their profiles. However, from the light 
gray zones to the surface parts, $\mathrm{Ca}$ and $\mathrm{Na}$ decrease gradually outwards by as much as $10 \%$ (though Al remains constant). The surface dark layers and the dark bands have smaller losses of $\mathrm{Ca}$ and $\mathrm{Na}$ than the white zones. The loss of $\mathrm{Ca}$ and $\mathrm{Na}$ corresponds with the increase of halloysite, which suggests that the insides of the prisms obtained halloysite from the plagioclase by leaching its $\mathrm{Ca}$ and $\mathrm{Na}$. The outer few millimeters of the surface dark layers show decreases in $\mathrm{Al}$ and $\mathrm{P}$ as well as $\mathrm{Ca}, \mathrm{Na}, \mathrm{K}$ and $\mathrm{Si}$. The loss of $\mathrm{Al}$ and $\mathrm{Si}$ is consistent with the sharp decrease in plagioclase content. However, the loss of plagioclase in the white zones was undetectable with $\mathrm{XRD}$, probably because the loss of $\mathrm{Ca}$ was only ever as much as $10 \%$.

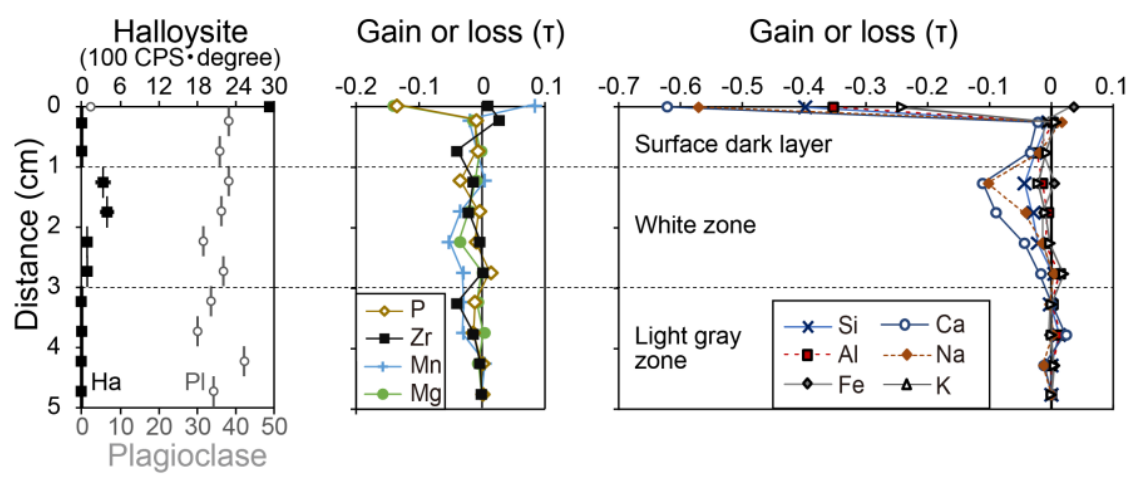

Fig. 2. Peak areas for plagioclase and halloysite (from XRD), and elemental transfer coefficients assuming that each innermost part is the original rock and that $\mathrm{Ti}$ is immobile.

\section{Discussion}

The cause of surface dark layers seems not to have been weathering or alteration, as some dark layers lack halloysite. Black rings or zones adjoining columnar joints are well known in basalts and andesites, and some have been regarded as due to the pore structures prior to weathering [9]. We presume that the surface dark layer immediately adjacent to the columnar joints changed rapidly into a solid state, and that this would have stopped the coalescence of micropores through Ostwald ripening.

A few centimeters inside the basaltic prisms at our study site we were able to observe "white zones" where there are open boundaries among crystal grains, and etched surfaces due to the alteration of plagioclase to halloysite. If halloysite had formed as a result of hydrothermal alteration following the eruption of lava at our study site, kaolinite and pyrophyllite should have accompanied it [10]. We infer, therefore, that the halloysite is the weathering product of plagioclase due to the movement of surface ground water.

The chemical reaction of the weathering of plagioclase to halloysite is controlled by the concentrations of $\mathrm{Al}, \mathrm{Ca}, \mathrm{Na}, \mathrm{Si}$, and $\mathrm{H}$ ions. Because $\mathrm{Na}, \mathrm{Ca}$ and $\mathrm{Si}$ have much higher solubilities than $\mathrm{Al}$, they diffuse and move out gradually to the joint surfaces, whereas the $\mathrm{Al}$ is less mobile. Thus, halloysite is formed in situ where the core of plagioclase (labradorite) dissolves as the result of the following incongruent weathering reaction: $\mathrm{Na}_{0.3} \mathrm{Ca}_{0.7} \mathrm{Al}_{1.7} \mathrm{Si}_{2.3} \mathrm{O}_{8}+3.6 \mathrm{H}_{2} \mathrm{O}+1.7 \mathrm{H}^{+} \rightarrow 0.3 \mathrm{Na}^{+}+0.7 \mathrm{Ca}^{2+}+\mathrm{Al}_{2} \mathrm{Si}_{2} \mathrm{O}_{5}(\mathrm{OH})_{4} \cdot 2 \mathrm{H}_{2} \mathrm{O}+$ $0.6 \mathrm{H}_{4} \mathrm{SiO}_{4}(\mathrm{aq})$. $\mathrm{Na}$ and $\mathrm{Ca}$ decrease in the rock as the amount of halloysite increases towards the joint surfaces. The weathering proceeded with positive feedbacks so that dissolution enlarged the pore spaces, thereby accelerating the supply of reactants to the residual plagioclase. The rock surfaces were supplied with diluted water through the columnar joints, and the pore water would have had lower concentrations of $\mathrm{Al}$ and Si ions, thus inducing the alteration of halloysite to gibbsite due to the following reaction: $\mathrm{Al}_{2} \mathrm{Si}_{2} \mathrm{O}_{5}(\mathrm{OH})_{4} \cdot 2 \mathrm{H}_{2} \mathrm{O} \leftrightarrow 2 \mathrm{Al}(\mathrm{OH})_{3}+2 \mathrm{SiO}_{2}(\mathrm{aq})+\mathrm{H}_{2} \mathrm{O}$ 
Taking a broad view, the distributions of $\mathrm{Ca}, \mathrm{Na}$, and halloysite in the prisms indicate that rock weathering is more intense closer to the columnar joints, which suggests that the weathering rate was limited by diffusion of the reactants and products in the porous rock. The effective diffusion coefficients in rocks are associated with porosity [11] and pore size [12]. Applying these ideas to our samples, we can see that diffusion in the surface dark layers is slower than in the light gray zones because of their smaller-sized pores, and thus they become the less-weathered rindlets.

From our results, the pore structure, cracks, and cross joints related to columnar-jointing are considered to be the dominant factors in the initial stage of spheroidal weathering. However, it is still not unclear that their formation processes and whether similar primary structures encourage spheroidal weathering in other types of igneous rock.

\section{Conclusions}

The columnar-jointed basalt of the Quaternary Ogura lava contains primary structures that resulted from cooling, which exerted strong controls on the development of spheroidal weathering. The basalt has been weathered chemically by the diffusion of oxygen and various ions in water that moved from the surrounding joints through the rock matrix. Olivine was oxidized to iddingsite from the outside of phenocrysts, and plagioclase laths were starting dissolution and transformed to halloysite. On the joint surfaces, halloysite also dissolves, and gibbsite forms. The weathering of plagioclase was less intense in the smallpore-size layers beneath the surfaces of columnar joints and some cross joints, resulting in the exfoliation of surface parts of the layers and internal cracks.

We thank E. Nakata, M. Watanabe, and K. Ueta of the Central Research Institute of Electric Power Industry for conducting the mercury intrusion porosimetry and XRF measurements. This work was supported by JSPS KAKENHI Grant Number JP17J09850 and by the Disaster Prevention Research Institute, Kyoto University.

\section{References}

1. C.D. Ollier, Z. Geomorphol. 11, 103-108 (1967)

2. H.L. Buss, M.I. Lebedeva, S.L. Brantley, Chem. Geol. 276, 129-143 (2010)

3. Y. Hirata, M. Chigira, Y. Chen, Earth. Surf. Proc. Land. 42, 657-669 (2017)

4. V. Moon, J. Jayawardane, Eng. Geol. 74, 54-72 (2004)

5. Takurayama Research Group, AGCJ 38, 143-160 (1984)

6. K. Furuyama, K. Nagao, K. Kasatani, S. Mitsui, AGCJ 47, 377-390 (1993)

7. A. Spry, J. Geo. Soc. Aust. 8, 191-216 (1962)

8. L.K. Smith, R.A. Milnes, Clay Clay Miner. 35, 418-428 (1987)

9. B. Guy, J. Volcanol. Geoth. Res. 194, 69-73 (2010)

10. A. Inoue, Formation of Clay Minerals in Hydrothermal Environments. 268-329 (Springer, Heidelberg, 1995)

11. C.T. Oguchi, Catena 58, 65-75 (2004)

12. K. Nishiyama, S. Nakashima, R. Tada, T. Uchida, Mining. Geol. 40, 323-336 (1990) 